Comparison star is $\mathrm{BD} .-3^{\circ} 5704\left(9^{\mathrm{m}} \cdot 5\right)$ whose position is

$$
1855.0 \quad 23^{\mathrm{h}} 40^{\mathrm{m}} 5^{\mathrm{s}} \cdot 2 \quad-3^{\circ} \quad 7: 6 .
$$

South following it is BD. $-3^{\circ} 5706\left(9 \mathrm{~m}_{2}\right)$ on the above date, with the $\mathrm{I} 2$ inch refractor, $I$ determined the $\Delta \alpha$ and $\Delta \delta$ of these two stars

$$
\Delta \alpha=\mathrm{o}^{\mathrm{m}} 2 \mathrm{I} \text {.06 (I } 2 \text { transits) } \Delta \delta=\text { I' }^{\circ} 7^{\prime \prime 6} \text { (2 measures) }
$$

Yerkes Observatory, 1906 Sept. $x$.

$$
\text { E. E. Barnard. }
$$

\title{
The nebula NGC. 6302 .
}

$$
\text { I860.0 } 17^{\mathrm{h}} 4^{\mathrm{m}} 17^{\mathrm{s}}-3^{6^{\circ}} 5^{6^{\prime}} \text {. }
$$

By E. E. Barnard.

This nebula was discovered by me in 1880 at Nashville, Tennessee, while hunting comets with my 5 inch refractor. Subsequently observing it with his 16 inch at Rochester N. Y., Swift found it to be triple.

In 1892 I examined and measured the nebula with the 36 inch of the Lick Observatory and found it to be a very remarkable object. With the great telescope it was seen to consist of three rather bright small nebulae. Two of the nebulae had faint streamers running north preceding, while the third, the following component, had two nebulous arches springing from it and extending some distance following. The entire nebula, especially the following part, looked like a ghostly bug of some kind; the third mass being the head and antennae. From its singular appearance, I have called it the Bug Nebulac. The enclosed drawing was made from three or four nights study of it with the 36 inch, and very fairly represents its remarkable appearance. Careful measures were made of the nebula, but the drawing is not from these measures. I also send a rough diagram which indicates the portions measured.

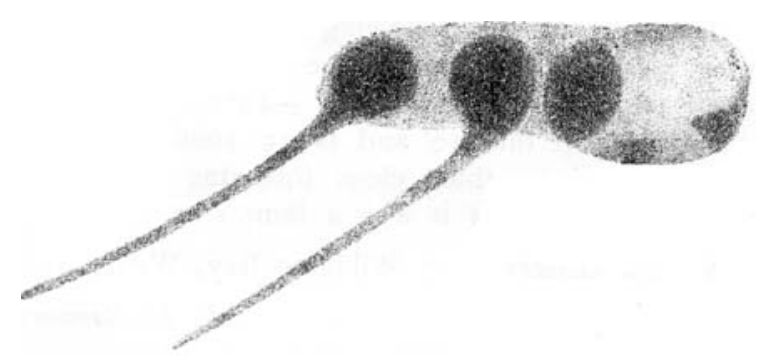

In the following measures the letters refer to those on the diagram.

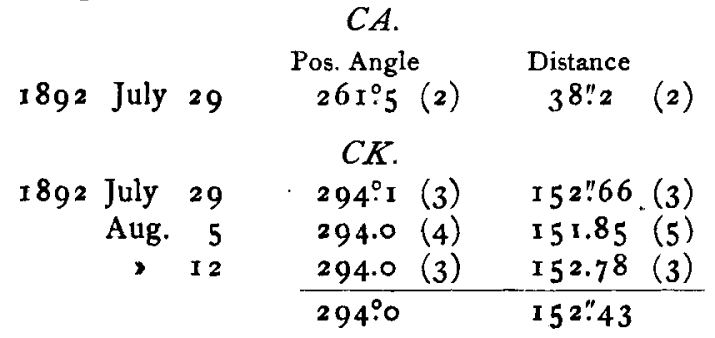

$K$ is a $13 \frac{1}{2}$ magnitude star n. p.

$C B$.

1892 July $29 \quad$ Dist. II"55 (2)
1892 July $29 \quad C P$. Dist. 28"3 I (2)

Yerkes Observatory, I906 Aug. 30 .

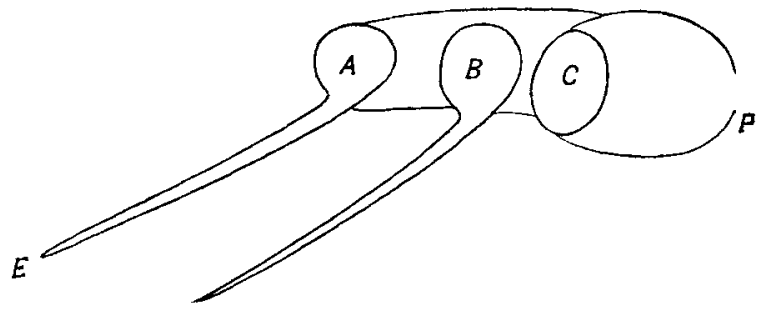

North

The figures in parenthesis represent the number of settings.

The $\mathrm{E}$ and $\mathrm{W}$ diameter of the brightest part of $C=8.7$, $C$ is somewhat elliptical.

Estimations were made of the relative brightness of the different parts of the nebula.

$$
\begin{aligned}
& C \text { is } 5 \text { times as bright as } B \\
& C \text { is } 4 \text { times as bright as } A .
\end{aligned}
$$

Another estimate made $B$ very slightly brighter than $A$.

The brightest part, $C$, was estimated to be of $x 2$ mag. The other two portions were about $14 \mathrm{mag}$.

Too much reliance must not be placed on the exactness of the position of this nebula as given in A. N. 2588 Bd. 108 p. 369 .
E. E. Barnard. 